\title{
Matthias Middell, Ulf Engel (dir.), Theoretiker der
}

\section{Globalisierung}

Leipzig : Leipziger Universitätsverlag, 2010, 475 p., $33 €$

\section{Guillaume Garner}

\section{CpenEdition}

\section{Journals}

Édition électronique

URL : http://journals.openedition.org/ifha/8176

DOI : 10.4000/ifha.8176

ISSN : 2198-8943

Éditeur

IFRA - Institut franco-allemand (sciences historiques et sociales)

Référence électronique

Guillaume Garner, « Matthias Middell, Ulf Engel (dir.), Theoretiker der Globalisierung », Revue de l'IFHA [En ligne], Date de recension, mis en ligne le 14 avril 2015, consulté le 22 septembre 2020. URL : http:// journals.openedition.org/ifha/8176 ; DOI : https://doi.org/10.4000/ifha.8176

Ce document a été généré automatiquement le 22 septembre 2020.

(CIFHA 


\title{
Matthias Middell, Ulf Engel (dir.), Theoretiker der Globalisierung
}

\author{
Leipzig : Leipziger Universitätsverlag, 2010, 475 p., $33 €$
}

Guillaume Garner

Si un concept connaît depuis deux décennies une fortune exponentielle, dans les médias comme dans les discours politiques ou dans le champ des sciences humaines et sociales, c'est bien celui de globalisation. Comme le soulignent dans une introduction très éclairante Matthias Middell et Ulf Engel, l'inflation du terme se révèle à vrai dire être un obstacle plus qu'un adjuvant à une meilleure compréhension des phénomènes désignés sous ce terme - ou sous celui (sans équivalent en allemand ou en anglais) de «mondialisation». Les approches sont en effet multiples et en partie cloisonnées, d'autant plus qu'un débat (fréquent dans les sciences humaines et sociales) oppose les tenants d'une vision de la globalisation comme réalité à ceux qui l'analysent avant tout comme un discours dont il s'agit de déconstruire les ressorts.

Là est précisément l'objectif de ce recueil dont les contributeurs sont presque tous des chercheurs (doctorants) de l'Institut des études globales et européennes de Leipzig, qui était dirigé par les deux éditeurs de ce livre: il s'agit de retracer les fondements théoriques et historiques des discours sur la globalisation en présentant quelques-uns des auteurs qui ont contribué, à des degrés et à des périodes variables, à l'élaboration de ces discours. Ont ainsi été retenus 26 auteurs, dont la liste ne représente évidemment pas un best-of des penseurs de la globalisation - auquel cas la nonsélection de Karl Marx, Immanuel Wallerstein ou Giovanni Arrighi serait étonnante. Il ne s'agit au contraire que du premier jalon d'un projet dont les éditeurs souhaitent développer sur la base de futures collaborations élargies.

Cette liste fournit en revanche un exemple de mental map des sciences humaines et sociales en Allemagne. Et cette carte mentale est pour le moins préservée du reproche de germanocentrisme, puisqu'un seul auteur allemand est présenté (Niklas Luhmann), l'Autriche étant représentée à travers Alfred Verdroß-Roßberg, tandis que deux auteurs français sont présentés (Fernand Braudel et Henri Lefèbvre). Mais le renvoi à une identité nationale est difficile pour nombre des auteurs présentés dont beaucoup 
ont un parcours biographique transnational (qui s'achève souvent par la détention d'une chaire dans une université nord-américaine), parcours biographique que la plupart des articles s'efforce reconstituer, suivant en cela les principes de méthode formulés en introduction.

Outre la largeur du spectre disciplinaire balayé, la principale qualité de ce recueil est l'aptitude de ses contributions à présenter de manière synthétique et pédagogique des œuvres complexes : de ce point de vue, les chapitres consacrés à David Harvey, Saskia Sassen et en particulier Niklas Luhmann sont particulièrement réussis. Et l'ampleur du spectre disciplinaire balayé permet de décloisonner les différentes approches de la globalisation : de ce point de vue également, ce recueil remplit pleinement ses objectifs initiaux.

INDEX

Index chronologique : Époque contemporaine

Thèmes : Historiographie/Méthodologie, Manuels/Ouvrages généraux/Outils de travail, Ouvrages transpériodiques

\section{AUTEUR}

GUILLAUME GARNER

ENS Lyon 